\title{
Experimental Study on Scavenging DPPH Free Radical Activity of Litsea Cubeba Oil
}

\author{
Yongguang $\mathrm{Bi}^{\mathrm{a}^{*}}$,Yanfen Zhang and Fan-sheng Kong \\ College of Pharmacy, Guangdong Pharmaceutical University, Guangzhou 510006, Guangdong, \\ China \\ abiyongguang2002@163.com
}

${ }^{*}$ Corresponding author

\section{Keywords: Litsea Cubeba Oil; DPPH; Antioxidant Activity; Examination}

\begin{abstract}
In order to verify the antioxidant activity of Litsea cubeba oil, the antioxidant activity of Litsea cubeba oil was determined by DPPH method. The experimental results showed that: Shancang The DPO free radical scavenging rate of Litsea cubeba oil was $86.33 \%$ at the concentration of $2.5 \mathrm{mg} / \mathrm{mL}$. Therefore, Litsea cubeba oil can be used as health food or medical food development research.
\end{abstract}

\section{Introduction}

China's Cangko products, although the high yield, but the overall level of production is low, mainly to the export of primary crude oil, Litsea cubeba oil utilization status, the main way low value exports can not achieve this advantage of China's resources, it is high cost, Output of the workshop mode. Due to the high alfalfa, in the heat, moisture and in the humid air easily oxidized into acid or rotten rotten, requiring the local acquisition, it has been used to extract the local soil distillation of about $2.5 \%$ citral crude oil, And then sent to the natural spice factory, distilled into about $75 \%$ of citral oil, export or other spices plant to further processing into different specifications of citral or ionone series of semi-synthetic spices products. Processing at low value monotonous, low level of use stage ${ }^{[1]}$. Although China is rich in resources, but the processing level is low, the scale of production is too small, monotonous varieties, automation, low degree of continuous, high production costs, poor quality, not only high-grade spices in the international market competition, Of the Litsea cubeba essential oil and its processed citral prices are very low, little benefit. In the comprehensive utilization of Litsea cubeba, the Chinese scientific workers have also carried out a multi-field research and exploration, but did not form a reasonable development system from the variety, cultivation and cultivation to the scientific extraction and separation, by-product processing and utilization of scientific and rational development system.

Litsea cubeba oil synthesis of high-level spices: Litsea cubeba oil is the main component of citral, aromatic plants essential oil is a high content of citral. Citral and acetone in the role of alkali condensation under the formation of pseudo-ketone ketone, and then by catalytic cyclization can be obtained ionone ketone, ionone in the industry widely used in the synthesis of vitamin E. Refined Litsea cubeba oil with fresh lemon fruit flavor, can be directly used for candy cakes, chewing gum, ice cream, beverages, sauce condiments, seasoning oil and baked goods such as seasoning incense ${ }^{[2]}$. Studies have shown that Litsea cubeba oil on Aspergillus flavus, Penicillium chrysanthemum, Mucor, Mildew and other mold have a strong antibacterial effect. The study found that Litsea cubeba oil has a strong antioxidant activity, better than ginger oil and cinnamon oil.

Litsea cubeba in the application of medicine: summer and autumn season, when the mountain Euphorbia fruit ripening can be collected, to foliage, dried, for cubeba eggplant medicine. Litsea cubeba with warm in the cold, qi pain effect, can be used for Wei Han caused by hiccup vomiting, abdominal pain and other symptoms, can also be used for cold hernia abdominal pain, cold and urinate and children with cold and dampness caused by urination Turbidity, but also the treatment of cold cold, cough, asthma, indigestion embolism ${ }^{[3]}$. With mangrove leaves smashed topical, can cure ganglion boil and swollen; Litsea cubeba root Jianshui hot or hot dip can treat rheumatoid bone 
pain, limb numbness, waist and leg disease and bruises. Litsea cubeba oil can also be used as synthetic vitamin $\mathrm{E}, \mathrm{K}, \mathrm{A}$ and other raw materials to play its role in medicine. Due to the unique role of Litsea cubeba oil in the treatment of disease, in clinical research is also a hot spot. In addition, Litsea cubeba also has asthma, anti-allergy, anti-heart often, anti-thrombosis, antibacterial, anti-virus, anti-vaginal trichomonas effect. It is foreseeable that the application of Litsea cubeba oil in medicine will also make progress.

Chinese medicine is often used for the stomach cold pain, hiccups vomiting embolism. Litsea cubeba function warm spleen and stomach, cold and pain, it is suitable for stomach cold pain, and stomach cold caused by hiccups, vomiting, abdominal distension and boredom embolism, often with galangal and other applications. Litsea cubeba's unique citral, can effectively inhibit the activity of Helicobacter pylori, so as to achieve the inhibition and kill the effect of Helicobacter pylori $^{[4]}$. To know that the general gastritis patients are containing Helicobacter pylori, and $\mathrm{H}$. pylori a large number of breeding may induce gastric cancer, so kill the Helicobacter pylori is very important, every day brewing 3-5 grams of corymbose tea drinking with the stomach is very benefit. At the same time Litsea cubeba is used to remove the bad breath of the ancient medicine, Litsea cubeba can be in addition to bad breath, because of its unique aroma can suppress the mouth of the odor, of course, it can remove the stomach heat effect. Most of the bad breath caused by stomach heat occurs in the stomach heat, food and other people's body. Office women often drink the original mountain Cangguo tea can eliminate bad breath, bring a fresh tone.

As a result of the safety, synthetic synthetic antioxidants (BHA, BHT) commonly used in the food industry are generally questioned and have been shown to be toxic and carcinogenic in the corresponding animal experiments. The United States and some countries have banned the use of artificial Synthetic antioxidants, many countries also limit the amount of its added, therefore, from the herbal medicine extraction of broad-spectrum, efficient and safe natural food antioxidants increasingly attention and become today's food, pharmaceutical research hot spots. Litsea cubeba oil, as a kind of natural organic antioxidants with great development prospects, is worthy of further study. Therefore, the extraction of Litsea cubeba oil from Litsea cubeba fruit and the antioxidant activity of Litsea cubeba oil can be studied. The wide application of such natural antioxidants provides a theoretical basis. In this paper, the antioxidant capacity of Litsea cubeba oil was determined by DPPH radical scavenging rate method.

\section{Materials and Methods}

Materials of the Test. Litsea cubeba fruit: Place of origin was Anhui Province, China; Absolute Alcohol: Tianjin Fu Yu Fine Chemical Co., Ltd.;

Experimental Apparatus. Swing High-speed Universal Pulverizer: Wenling Grand Forestry Machinery Co., Ltd.; AY120 Electronic Analytical Balance: Shimadzu Corporation; KH-400KDB High Power CNC Ultrasonic Cleaner: Kunshan Hechuang Ultrasonic Instrument Co.; SHZ-D (III) Circulating Water Pumps: Gongyi Instrument Co., Ltd.; RE-52AA Rotary Evaporator: Shanghai Yarong Biochemical Instrument Factory.

\section{Determination of Antioxidant Activity of Litsea Cubeba Oil}

1. Determination of DPPH Free Radical Scavenging Activity

(1) Preparation of DPPH solution

Weigh $2.0 \mathrm{mgDPPH}$, dissolved in absolute ethanol solution and set to $50 \mathrm{~mL}$ volumetric flask, that was $0.04 \mathrm{mg} / \mathrm{mL}$ DPPH ethanol solution, placed in the dark, is now available.

(2) preparation of Litsea cubeba oil solution

$0.025 \mathrm{~g}, 0.075 \mathrm{~g}, 0.100 \mathrm{~g}, 0.125 \mathrm{~g}$ Litsea cubeba oil were accurately weighed and reduced to 50 $\mathrm{mL}$ with absolute ethanol to obtain $0.5 \mathrm{mg} / \mathrm{mL}, 1 \mathrm{mg} / \mathrm{mL}$, respectively. $1.5 \mathrm{mg} / \mathrm{mL}, 2 \mathrm{mg} / \mathrm{mL}$, $2.5 \mathrm{mg} / \mathrm{mL}$ of a series of Litsea cubeba oil.

(3) Determination method

A solution of $3.0 \mathrm{~mL}$ of Litsea cubeba oil was added to anhydrous ethanol containing $0.04 \mathrm{mg} /$ $\mathrm{mL}$ DPPH, mixed with, shaking at room temperature for $30 \mathrm{~min}$, and then detected at a wavelength 
of $517 \mathrm{~nm}$ by reference to the method of Brandwilliams et al. Blank for anhydrous ethanol zero. The clearance rate is calculated as:

DPPH radical scavenging rate $(\%)=[$ Ac- $(\mathrm{Ai}-\mathrm{Aj})] / \mathrm{Ac} \times 100 \%$

Where: Ac - control 3.0mL DPPH solution plus 3.0mL absolute ethanol absorbance at $517 \mathrm{~nm}$;

Ai-3.0mL Litsea cubeba oil solution with $3.0 \mathrm{~mL}$ DPPH solution at $517 \mathrm{~nm}$ absorbance value;

$\mathrm{Aj}-3.0 \mathrm{~mL}$ Litsea cubeba oil solution with $3.0 \mathrm{~mL}$ absolute ethanol at $517 \mathrm{~nm}$ absorbance value; Using the Microsoft Excel fitting regression equation, when R2>0.9, we get the equation and take the $\mathrm{Y}$ value of 50 to obtain the IC50, that is, the mass fraction of Litsea cubeba oil with the radical scavenging rate of $50 \%$. The smaller the IC50 value indicates that the antioxidant The stronger the ability.

\section{Results and Discussion}

The Activity of Scavenging DPPH Free Radicals of Litsea Cubeba Oil. In this experiment, the DPPH colorimetric method was used to study the scavenging effect of each percentage of Litsea cubeba oil emulsion solution on DPPH. The results are shown in Fig.1.

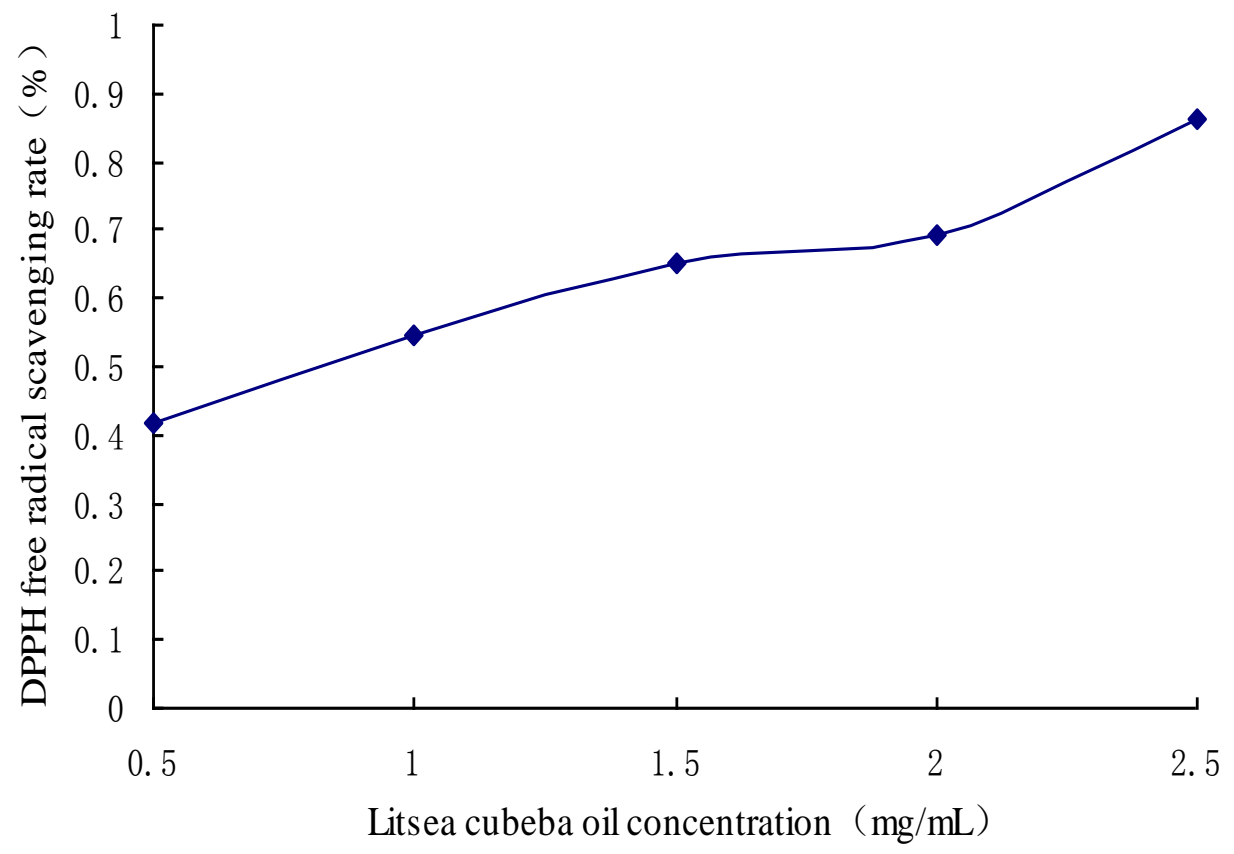

Figure 1. Determination of DPPH scavenging rate of Different concentrations

It can be seen from Fig. 1 that Litsea cubeba oil has a high DPPH free radical scavenging ability, and the DPPH scavenging ability of Litsea cubeba oil has a linear relationship with the concentration of Litsea cubeba oil. According to the experimental data, The concentration was correlated with the DPPH free radical scavenging rate, and the regression equation was: $\mathrm{y}=$ $0.2076 \mathrm{x}+0.3226(\mathrm{R} 2=0.9706)$ and IC50 $=0.85 \mathrm{mg} / \mathrm{mL}$. When the mass concentration of Litsea cubeba oil was above $0.85 \mathrm{mg} / \mathrm{mL}$, the DPPH clearance rate was over $50 \%$. When the mass concentration was $2.5 \mathrm{mg} / \mathrm{mL}$, the DPPH clearance rate was $86.33 \%$, which indicated that Litsea cubeba oil had strong DPPH scavenging ability. With the increase of the concentration of Litsea cubeba oil in ethanol solution, the curve showed a clear upward trend. The higher the clearance rate, the stronger the antioxidant capacity, the greater the concentration of Litsea cubeba oil, Its antioxidant activity is stronger, showing a good dose-dependent relationship.

Studies have shown that vitamin E, phytosterols can act as hydrogen donors, remove the original free radicals, generate new free radicals and provide a single electron conjugate with the benzene ring, make it stable, is a good free radical scavenger, and fish shark Alkene is a single-phase oxygen quencher and a free radical scavenger, but because of the low levels of these endogenous 
antioxidants, the correlation coefficient is small and the proportion of peanut vitamin $\mathrm{E}$ is proportional And is not conducive to its role in the oxidation of oil, and squalene are all oxidized into a co-oxidant, therefore, peanut oil has a certain antioxidant effect, but the antioxidant is very low. And soybean oil in the natural pigment, vitamin $\mathrm{E}$ and other antioxidants may also be due to its low content, making its antioxidant effect. The antioxidant activity of Litsea cubeba oil is not clear, but many studies have proved that it has strong antioxidant activity, and because of the high antioxidant activity, One step of the research of Litsea cubeba oil, Cangsacus oil extraction date than pepper oil earlier two weeks, the experimental measured Litsea cubeba oil reduction force is slightly weaker than pepper oil, may be because the storage time is too long, Litsea cubeba Oil oxidation resistance to a certain extent weakened.

\section{Conclusion}

The DPPH free radical scavenging rate and reducing ability of Litsea cubeba oil were studied. It was proved that Litsea cubeba oil had strong antioxidant activity, and DPPH clearance rate were linearly related to the concentration of Litsea cubeba oil. The higher the concentration, the higher the DPPH clearance rate, the stronger the reducing ability, and the stronger the antioxidant activity.

The study found that many diseases of the organism are related to the oxidative damage of the free radicals to the body. The natural antioxidants have great development potential, combined with modern science and technology and traditional Chinese medicine theory, and deeply study the active components of Litsea cubeba oil antioxidant and Mechanism of action, the formation of the theoretical system of integrated traditional Chinese and Western medicine, can make the value of Litsea cubeba oil to a deeper level of expression. In recent years, the synergistic effect of antioxidants has become a research hotspot. Many studies have found that the effect of "complex natural antioxidant" is better than "single type natural antioxidant", and it can find synergistic effect with Litsea cubeba oil Antioxidant, and its optimal combination of concentration has a certain significance. For the study of the antioxidant effects of Litsea cubeba oil, we must also pay attention to its antioxidant components in the body and the role of differences in food, whether it is medicine, or in food and other industries, optimize its extraction process, in-depth development The use of Litsea cubeba oil antioxidant, still need to conduct further research.

\section{Acknowledgements}

This work is supported by Guangdong Province Science and Technology Project(No. 2016A020210133)

\section{References}

[1] Dudai N., Weinstein Y, Krup M., et al. Citral is a new inducer of caspase-3 in tumor cell lines[J].Planta Medica, 2005, 71(5): 484-488.

[2] Amer A., Mehlhorn H.. Repellency effect of forty-one essential oils against Aedes, Anopheles, and Culexmosquitoes[J].ParasitologyResearch,2006, 99(4):478-490.

[3] Hwang J.K., Fitoterapia,Choi E.M., Lee J. H.. Antioxidant activity of Litsea cubeba[J].200576(7-8): 684-686.

[4] Mikkola J. P , Warna J., V'n-tanen P , et al. Effect of internal diffusion inionic liquid catalysts: interaction with kinetics[J].Industrial and Chemistry Research, 2007, 46(12):3932-3940. 